\title{
NUMERICAL MODELLING OF BEHAVIOUR OF SURFACE FINISHING OF COMPOSITE MATERIALS
}

\author{
Josef Vosáhlo', Martina Syrovátková', Michal Petrůำ \\ 1 Technical University of Liberec, Studentská 2, 46117 Liberec, Czech Republic, e-mail: josef.vosahlo@tul.cz, \\ martina.syrovatkova@tul.cz, michal.petru@tul.cz
}

Received: 2017.07.26

Accepted: 2018.02.01

Published: 2018.03.01

\begin{abstract}
The article describes and compares the course of the resistance test of a treated surface against the impact of gravel with the model of the test process. The two series of composite samples with surface treatment underwent a so-called gravel test, followed by the evaluation of the test results. Simultaneously with the tests, the material models of the tested composites were created. The input values obtained were used to create a FEM model. The model describes the response of the surface treatment to the impact of the object i.e. gravel of the given size and weight/number. The modelling results were compared with the results of real tests.
\end{abstract}

Keywords: surface finishing, gravel, composite, material models, FEM model.

\section{INTRODUCTION}

Key performance drivers in automotive coatings are quality, cost, and environmental compliance. Quality and cost are addressed by more efficient coating processes and a higher degree of automatization. Automotive coating processes represent the cutting edge of application technology and paint formulas, as discussed elsewhere [2, 9]. Since the beginning of the twentieth century, car paints industry has undergone breakthroughs in material and technology. Initial manual paint application, sanding and polishing of layers were time consuming. Post-war mass production of transport equipment and development of the chemical industry has shifted paints and coating systems to a different level. The number of layers has been reduced and new ways of applying them to bodywork surfaces have been developed. Corrosion protection has greatly improved and the lifetime and the top-coat durability have been extended. At the same time, there are significant changes in paint technology and spray application, as discussed by Streitberger [9]. For endusers, chipping of coatings is particularly unac- ceptable on major sections of the automobile surfaces. The requirement for damage resistance of the lacquer or the coating system was quantified by means of a gravel test. To measure the stonechip resistance of coatings, more than twenty different test methods were developed. Standard SAE evaluates damage of coating systems using gravel; Standard VDA evaluates the damage of coating systems using steel grit as discussed by Buter [3]. The temperature has a great effect on the properties of the paint. Low temperature leads to a decrease in resistance and easier damage to the paint. The knowledge of relation between stone-chip resistance (properties of coating system) and other mechanical properties is very important. The dynamic mechanical thermal analysis (DMTA) used to describe structure-property relationships of coatings, as discussed by Lonyuk [6] when defining range impact velocity, angle and temperature). Layered double hydroxide (LDH)-based polymer composites are readily accessible materials and able to impart impact resistance to automotive coatings, as discussed by Hintze-Bruening [4]. Another quantitative testing methodology can be used to study the damage of 
polymeric coatings. The effects of coating ductility and thickness of acrylic polymers coated on steel substrate were investigated, as discussed by Browning [1]. The test was performed at both normal and low temperatures. The article describes the comparison of the course of the gravel impact resistance test with the model of the test process.

\section{MATERIALS AND METHOD}

Composite samples were made of carbon prepreg with an epoxy resin. Prepreg fabric (twill 2 $\mathrm{x} 2$ weave) is made of high strength carbon $3 \mathrm{~K}$, density $1.77 \mathrm{~g} / \mathrm{cm}^{3}$. The nominal epoxy resin density was $1.18 \mathrm{~g} / \mathrm{cm}^{3}$, and a glass transition temperature of $110^{\circ} \mathrm{C}$. The nominal resin weight was $422 \mathrm{~g} / \mathrm{m}^{2}$, the nominal resin content was $42 \%$. The gravel used for surface quality testing had the prescribed total weight according to the Standard. Their size ranged from 9 to $16 \mathrm{~mm}$.

\section{EXPERIMENT}

Test sample was located in the Gravelometer, and air pressure was used to move the gravel on the surface of sample by ASTM D3170 method (Standard Test Method for Chipping Resistance of Coatings [1]). This method was used to test the surface finish of the composite (lacquer) against the impact at different temperatures, as discussed by Petru [7]. The Standard describes test conditions (temperature, air pressure, number and size of gravel, size and number of samples). Two sets of composite samples with lacquered surface were prepared (size $100 \times 150 \times 1.35 \mathrm{~mm}$ ). The conditioning of the samples was carried out at temperatures of $-20 \pm 5^{\circ} \mathrm{C}$ and room temperature $25 \pm 5^{\circ} \mathrm{C}$. The samples were fastened to the instrument holder and test was performed, test device is showed in the Fig.1a and Fig.1b.

The test samples were conditioned for 24 hours at room temperature. The adhesive tape was applied as follows. All loose fragments of the coating were pulled off by the removal of the tape. Areas of $25.4 \mathrm{~mm} \times 25.4 \mathrm{~mm}(1 \times 1 \mathrm{inch})$ were evaluated on the surface of the samples. The appearance of the test sample is possible to evaluate using two methods: Comparison to the standard and visual examination (counting all defects and damaged areas).

\section{Visual comparison to the Standard procedure:}

The routine laboratory examinations use the comparison with chipping standards (it's seen on Fig.2). Standards show the lowest acceptable number of damage of one size. It is possible to use more Standards because the damage does not have only one size. Standards superimpose, the result of the test is a combination of used standards sorted according to the frequency of defects rate in descending order.

\section{Visual examination:}

Standard ASTM D3170 has described defect marking system. The examined area was 25.4 $\mathrm{mm} \times 25.4 \mathrm{~mm}$, four examined areas were on the surface of each sample. All chips have been measured and counted in the defined area (Fig.3).

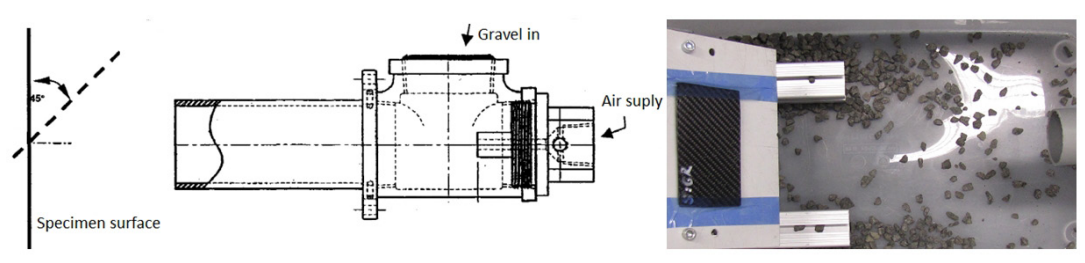

Fig. 1. a) Schema of Gravelometer (by ASTM D3170); b) Sample in a box

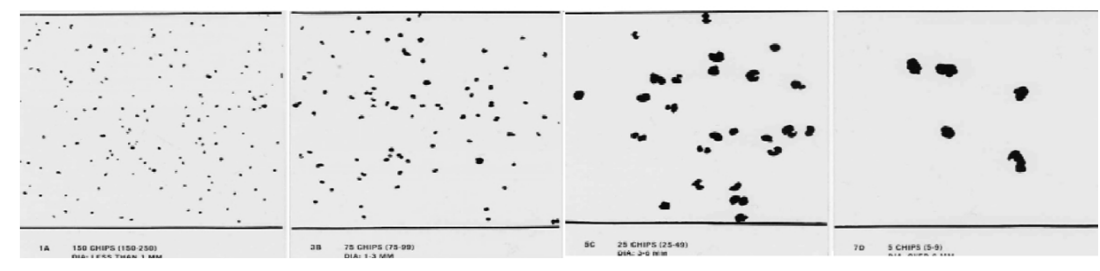

Fig. 2. Representation of chipping standards by SAE EA-400 


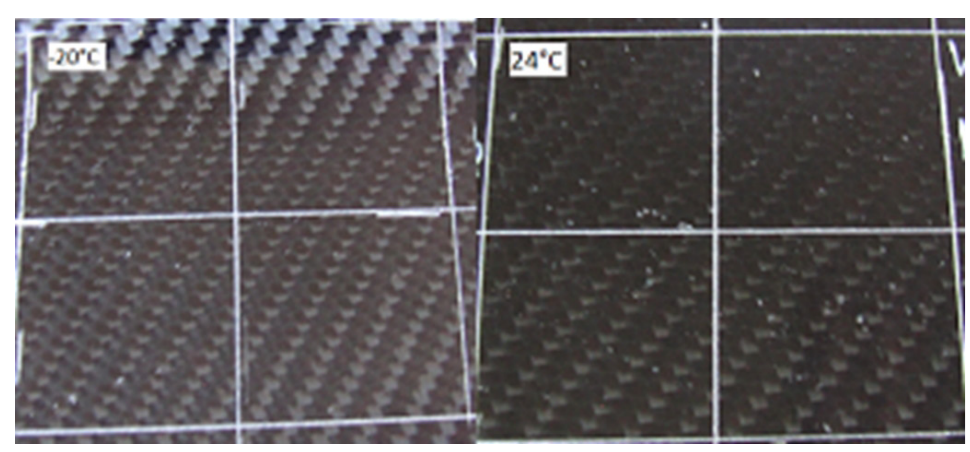

Fig. 3. Samples after chipping resistance of coatings test a) at $-20^{\circ} \mathrm{C}$ b) at $24^{\circ} \mathrm{C}$

The resulting combinations (number/size) were sorted in a descending order according to the frequency of the defects.

\section{FEM model}

FEM model for the description and study of the mechanical properties of the carbon composites samples is based on analytical models (Chamis and Halpin-Tsai models), as discussed by Jirásek [5]. Elastic constants E22, G12, G23 (1-4) can be obtained from simulations, which can be compared with a numerical model, as discussed by Wang [10]. Chamis model to calculate other elastic constants introduced into the solution to the square root of volumetric fibers $\sqrt{V^{f}}$; fibers are incompressible in equations $(2,4,5)$, which in accordance to the law of conservation of mass. Physical parameters for FEM model are shown in Tab.1.

$$
\begin{gathered}
\frac{d \sigma_{11}}{d \varepsilon_{11}}=V^{f} \frac{d \sigma^{f}}{d \varepsilon^{f}}+V^{m} \frac{d \sigma^{m}}{d \varepsilon^{m}} \Rightarrow \\
\Rightarrow E_{11}=V^{f} E_{11}^{f}+V^{m} E^{m} \\
E_{22}=\frac{E^{m}}{1-\sqrt{V^{f}}\left(1-E^{m} / E_{22}^{f}\right)} \\
v_{12}=V^{f} v_{12}^{f}+V^{m} v^{m}
\end{gathered}
$$

$$
\begin{aligned}
G_{12} & =\frac{G^{m}}{1-\sqrt{V^{f}}\left(1-G^{m} / G_{12}^{f}\right)} \\
G_{23} & =\frac{G^{m}}{1-\sqrt{V^{f}}\left(1-G^{m} / G_{23}^{f}\right)}
\end{aligned}
$$

\section{RESULTS}

According to ASTM D 3170 Chipping Resistance of Coatings prescribes sample dimensions $100 \times 150 \times 1.35 \mathrm{~mm}$, but for simplification, the model was reduced to $50 \times 50 \times 1.35 \mathrm{~mm}$. The samples were mounted on a test pad at the angle of $45^{\circ}$. Gravel models of about an average dimension of $12.5 \times 12.5 \times 12.5 \mathrm{~mm}$ were randomly distributed at the distance of $350 \mathrm{~mm}$ from the test sample, Fig.4a. The development of CAD model followed after the mechanical resistance test of the varnished composite surface. The model was imported into ANSYS simulation program. A motion study was chosen to model the impact of gravel on the samples surface. The mechanical characteristics of the material (elastic modulus, shear modulus and Poisson ratio) were inserted into the model; the characteristics are shown in

\begin{tabular}{|c|c|c|c|c|c|c|c|}
\hline \multirow{2}{*}{ Material } & \multirow{2}{*}{$\begin{array}{l}\text { Density } \\
{\left[\mathrm{kgm}^{-3}\right]}\end{array}$} & \multicolumn{2}{|c|}{$\begin{array}{c}\text { Elastic modulus } \\
{[\mathrm{GPa}]}\end{array}$} & \multicolumn{2}{|c|}{$\begin{array}{c}\text { Shear modulus } \\
\text { [GPa] }\end{array}$} & \multicolumn{2}{|c|}{$\begin{array}{c}\text { Poisson ratio } \\
{[-]}\end{array}$} \\
\hline & & $E_{11}$ & $E_{22}$ & $G_{12}$ & $G_{23}$ & $V_{12}$ & $V_{23}$ \\
\hline Epoxy Carbon & $1750 \pm 15$ & 29 & 9.45 & 5.5 & 3.9 & 0.27 & 0.4 \\
\hline Stones & $2600 \pm 37$ & 35 & - & 15 & - & 0.12 & - \\
\hline Structural steell & 7850 & 200 & - & 76.923 & - & 0.3 & - \\
\hline
\end{tabular}
Table 1. The model was divided into a rigid and flexible part for simplicity. The material properties of the gravel were used in the rigid part of the model. Orthotropic material model was used in

Table 1. Physical parameters of numerical model 


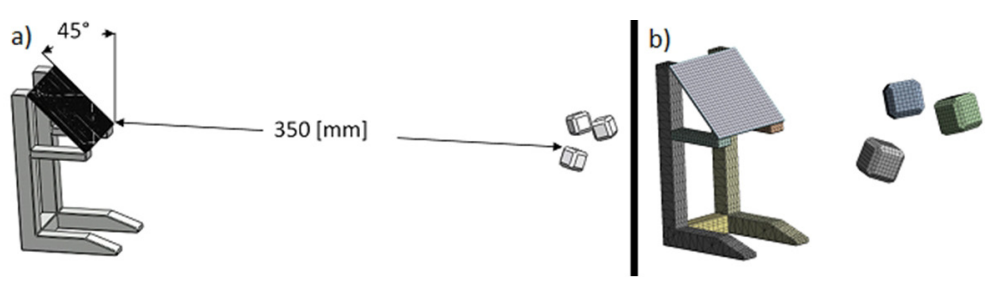

Fig. 4. a) Imported geometry with description, b) Meshing model

the flexible part. Bonded contacts were distributed between the sections of the model in the points of mutual contact. The contact parts of the model between the stand and the composite sample have formed bonded contacts. Friction contacts with a coefficient of 0.4 were inserted between the gravel model and the composite sample. In these contacts, input values were modified as the Normal Lagrange formula. The mesh was divided into individual parts; a mapped network of elements sized $2 \mathrm{~mm}$ was introduced into the composite sample. Combination of mesh and mapped face sizing of $2.0 \mathrm{~mm}$ was introduced on the supported frame. Combined mapped mesh and face sizing elements of about $1.5 \mathrm{~mm}$ was inserted in the part with gravel. A mesh with a total of 12586 nodes and 3109 elements was created throughout the entire model. Ansys program allows you to control the mesh and that works in principle derived directly from $\frac{A_{l} \cdot f_{i}}{\left|\vec{A}_{i}\right|\left|\vec{f}_{i}\right|} \frac{A_{i} c_{i}}{\left|\vec{A}_{i}\right|\left|\vec{c}_{i}\right|}$ computed for each face $i$. For the face it is computed as the minimum of $\frac{A_{i} \cdot e_{i}}{\left|\vec{A}_{i}\right|\left|\vec{e}_{i}\right|}$ computed for each edge. Where Ai is the face normal vector and $\mathrm{fi}$ is a vector from the centroid of the cell to the centroid of that face, and ci is a vector from the centroid of the cell to the centroid of the adjacent cell, where ei is the vector from the centroid of the face to the centroid of edge. The boundary conditions had the task of limiting motion and rotation in all directions and were located at the bottom of the model. Gravel models moved at the speed of $0.77 \mathrm{~m} / \mathrm{s}$. The temperature boundary conditions of $24^{\circ} \mathrm{C}$ and $-20^{\circ} \mathrm{C}$ were set for the modelling of tests. Changes in maximum strain and maximum deformation were observed when the gravel hit the painted surface at a time step of $0.26 \mathrm{~s}$. Results of deformation and contact stress are shown in the Fig.5-9 and in the Tab.2.

\section{CONCLUSION}

The article describes the comparison of the course of the resistance test of treated surface against gravel impact with the FEM model of the test process. The gravel test was evaluated according to the standard ASTM D3170, with the results summarized in the Table 2. Chips of the given size were counted on each of samples and the samples were classified into individual groups according to the damage. Samples were classified by the Standard as follows: A4 (size of chips to $1 \mathrm{~mm}$ ), B7 (size of chips to $3 \mathrm{~mm}$ ). The temperature boundary conditions of $24^{\circ} \mathrm{C}$ and $-20^{\circ} \mathrm{C}$ were determined for the modeling of tests. The models of gravel moved at the speed of $0.77 \mathrm{~m} / \mathrm{s}$. Changes in maximum strain and maximum deformation were observed when the gravel hit the painted surface at the time step of $0.26 \mathrm{~s}$. Damage to the coating system on surface of samples is seen in the Fig.5. The FEM model results were in good agreement with the experiment.
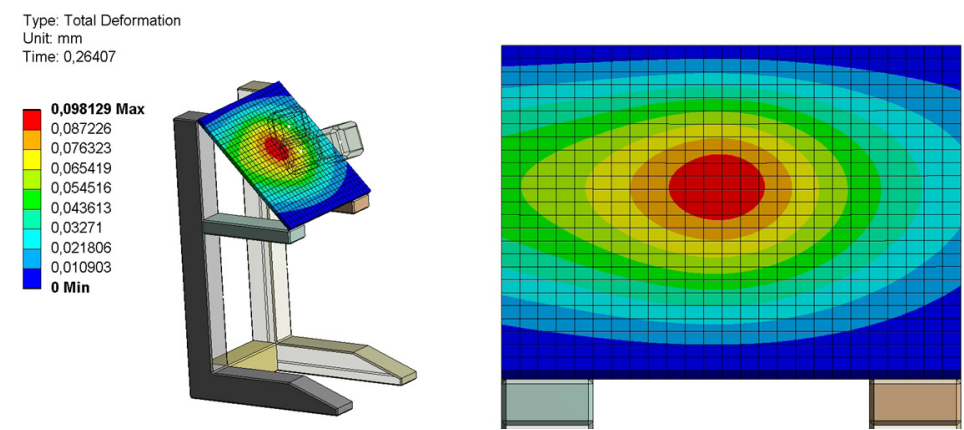

Fig. 5. Results of evaluation of the coating chipping resistance 

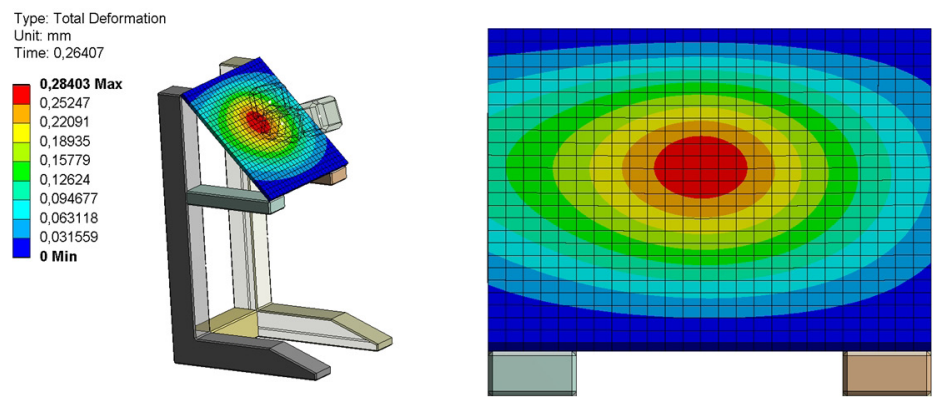

Fig. 6. Result FEM: Maximal deformation at $-20^{\circ} \mathrm{C}$
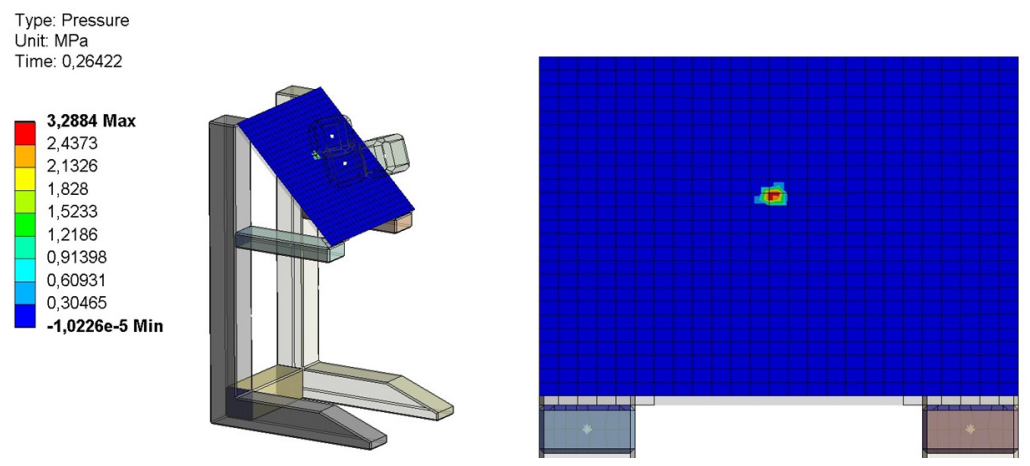

Fig. 7. Result FEM: Maximal deformation at $24^{\circ} \mathrm{C}$
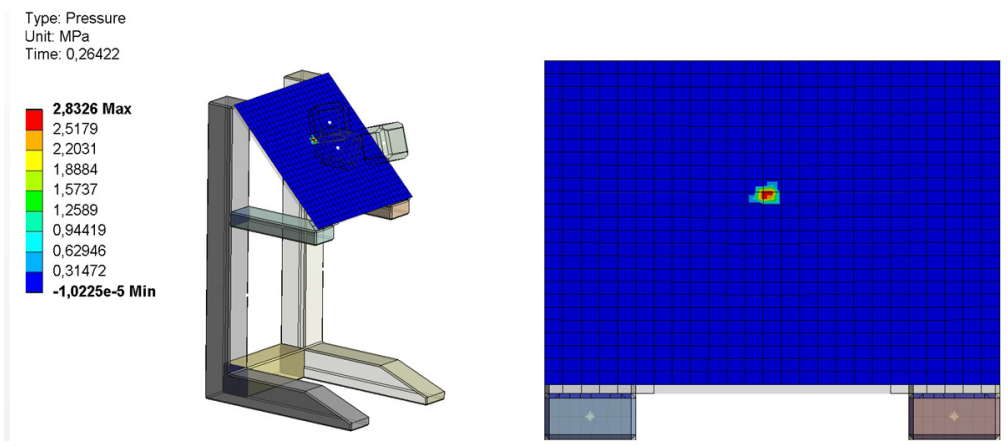

Fig. 8. Result FEM: Maximal contact stress at $-20^{\circ} \mathrm{C}$
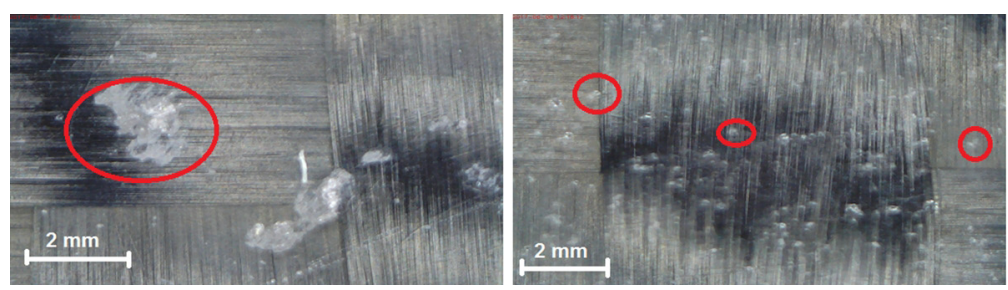

Fig. 9. Result FEM: Maximal contact stress at $24^{\circ} \mathrm{C}$

Table 2. Measured values

\begin{tabular}{|c|c|c|c|c|c|}
\hline Temperature $\left[{ }^{\circ} \mathrm{C}\right]$ & Deformation $[\mathrm{mm}]$ & $\begin{array}{c}\text { Real deformation } \\
{[\mathrm{mm}]}\end{array}$ & $\begin{array}{c}\text { Contact stress } \\
{[\mathrm{MPa}]}\end{array}$ & \multicolumn{2}{|c|}{ Samples classification } \\
\hline-20 & 0.087 & 0.107 & 3.288 & $\begin{array}{c}56 / 1 \mathrm{~mm} \\
11 / 3 \mathrm{~mm}\end{array}$ & $60 / 1 \mathrm{~mm} 15 / 3 \mathrm{~mm}$ \\
\hline 24 & 0.284 & 0.327 & 2.832 & $64 / 1 \mathrm{~mm} 17 / 3 \mathrm{~mm}$ & $61 / 1 \mathrm{~mm} 10 / 3 \mathrm{~mm}$ \\
\hline
\end{tabular}




\section{Acknowledgment}

The results of this project LO1201 were obtained with co-funding from the Ministry of Education, Youth and Sports as part of targeted support from the "Národní program udržitelnosti I" program.

\section{REFERENCES:}

1. ASTM D3170: Standard Test Method for Chipping Resistance of Coatings.

2. Browning R.L., Lim G.-T., Moyse A., Sue H.-J., Chen H., Earls J.D. Quantitative evaluation of scratch resistance of polymeric coatings based on a standardized progressive load scratch test, Surface and Coatings Technology, Volume 201, Issue 6, 4 December 2006, 2970-2976.

3. Buter R. and Wemmenhove A. Automotive waterborne surfacer with improved stone-chip resistance, Progress in Organic Coatings, 22, 1993, 83-105.

4. Hintze-Bruening H., Troutier-Thuilliez A.-L., Ler- oux F. Layered particle-based polymer composites for coatings: Part II-Stone chip resistant automotive coatings, Progress in Organic Coatings, Volume 64, Issues 2-3, February 2009, 193-204.

5. Jirásek M., Bažant Z. Inelastic analysis of structures, Wiley, 2002.

6. Lonyuk M., Bosma M., C.A.M. Vijverberg, Bakker A., Janssen M.: Relation between chip resistance and mechanical properties of automotive coatings, Progress in Organic Coatings 61, 2008, 308-315.

7. Petru M., Syrovatkova M., Martinec T., Lepsik P. Analysis of changes in the surface quality of a UD prepregs composite due to mechanical loading, Material Science Forum, 818 (1), 2015, 109-112.

8. Talia M., Lankarani H., Talia J.E. New experimental technique for the study and analysis of solid particle erosion mechanisms, Wear pp. 225-229, 1999, 1070-1077.

9. Streitberger H.J., Dössel K.F. Automotive paints and coatings, Wiley, 2006, ISBN 978-3-527-31296-2.

10. Wang H.R., Wang W., Gao J.O. Materials Letters 64, 2010, 219-221. 